Ethnic Studies Review Volume 26: 2

\title{
RACE, SEX, AND REDEMPTION IN MONSTER'S BALL
}

\author{
Celeste Fisher \\ Marymount Manhattan College \\ and \\ Carol Wiebe \\ Marymount Manhattan College
}

In this paper, we explore the way that interracial relationships between blacks and whites come to be represented as problematic for mainstream audiences. By looking specifically at the film Monster's Ball (2001), we examine how race is used to identify and characterize our culture's standard protagonist, the white male, and at how white male sexuality is constructed through the black female. Particularly striking in this film is how the social and institutional structures that create and reiterate problems of race are used to characterize the movie's central protagonists, yet then evaded and submerged in the discourse of romance.

When in the fifties Nabakov described the difficulty of selling Lolita to publishers, he explained that the topic was among "three themes which are utterly taboo as far as most American publishers are concerned. The two others are a Negro-White marriage which is a complete and glorious success resulting in lots of children and grandchildren; and the total atheist who lives a happy and useful life, and dies in his sleep at the age of 106...."

Nabakov had a point. It is still difficult to come across a 
media representation of the interracial couple and impossible to think of any such romance portrayed as unproblematic. Films that center an interracial couple present narratives of the "problem" romance-the socially significant problem film, which is significantly about race.

This study is an examination of the way these interracial relationships come to be represented as problematic for mainstream audiences. By looking specifically at Monster's Ball (Mark Forster, 2001), we are going to explore how race is used to identify and characterize our culture's standard protagonist, the white male, and at how white male sexuality is constructed through the black female. Particularly striking in the case of Monster's Ball is how the social and institutional structures that create and reiterate problems of race are used to characterize the movie's central protagonists yet then evaded and submerged in the discourse of romance. While the social aspects of racism come across as "natural" or given, the problems associated with race are formulated as problems concerning certain individuals. Fortunately these problems can be rectified with individual redemption, which occurs in the course of finding romance.

Monster's Ball presents the unlikely relationship between Hank Grotowski (Billy Bob Thornton), a Georgia corrections officer, and Leticia Musgrove (Halle Berry), the wife of a man whose execution Hank helps to conduct. Hank's father, a classic racist, is a retired corrections officer, and Hank's son, Sonny, is learning the ropes. Hank meets Leticia while she as at her job, waitressing. In the course of the film Leticia loses her husband and her job; her twelve-year-old son, Tyrell, is hit by a car and killed, and she is evicted from her home. In the meantime Hank's son commits suicide and later, when romantic possibilities with Leticia are threatened by his father's racist remarks, Hank puts his father in a home. While the relationship between Hank and Leticia happens by chance, its foreground is a sense of shared loneliness and loss, a sense of their mutual, desperate need.

Given its setting in the South and the narrative premise of the penal institution and a black man on death row, this movie would ostensibly appear to be about the problems of social justice in a racist environment and of the impact of institutionally sanctioned executions. Not only the family of the executed man 


\section{Ethnic Studies Review Volume 26: 2}

but those whose job it is to perform the execution are the characters of this narrative-the individuals who, in the end, will bear the burden of surviving the execution. While the issues of racial injustice or the problems of institutionalizing executions lends to the film a certain credibility, the film's center is the narrative of Hank's and Leticia's relationship. As such it sideswipes these issues and becomes instead the story of a white man's transformation-his overcoming of masculinist authority, of emotional alienation and bigotry by discovering sexual love with a black woman. Indeed. Love conquers all, even racism.

The film treats the discourse of romance and how race is constructed through renderings of heterosexual sex and desire. Monster's Ball, read as a typical romantic film, is a male weepie with a sort of happy ending. As with most romantic films the romantic leads are presented through a linking of two narrative strands. Here the first, central strand is that of the white male protagonist, Hank. As the credits roll over a shot of Hank sleeping, we see images of tombstones, of Hank driving, of a typical truck stop. Hank wakes up, vomits, and drives to the local diner. Unasked, the waitress brings him chocolate ice cream along with a plastic spoon. She sits down to chat as she pours him his coffee, which he takes black.

This opening sequence establishes, first, that Hank is a tormented soul. Not only is he plagued by insomnia, when he awakes from sleep he vomits. We know this is characteristic of Hank because he is evidently a regular at the diner; he has developed regular habits in order to cope. The scene also establishes that he is a likeable guy; in a friendly, non-intimate way, the waitress knows and likes him. At this point there is no reason to assume that Hank is bigot or even an insensitive jerk of a father. These characteristics are introduced later, almost as secondary or inconsequential characteristics. As such they become dispensable, attitudes that, like his uniform, are easily shed when he goes through his true romance transformation.

Leticia, on the other hand, is first introduced to us as wife of a condemned man. What the husband is guilty of is never specified and, indeed, becomes irrelevant. The husband, first seen talking to their son on the day before his execution, tells his son he is a bad man. He becomes just one more black man who 
cannot get it together. As with Samuel Jackson in Changing Lanes (Roger Michell, 2002) or even Denzel Washington in John $Q$. (Nick Cassavetes, 2002) he becomes a stand in for the black man who, beaten down by the system, has been unable to provide for his wife and children the good life they deserve. That Leticia is shown primarily as a wife and mother is completely in keeping with the way women are typically characterized-through their relationships with men and their status as mothers. Leticia, a black woman, is no exception. Joining together the two narrative strands of Leticia and Hank is the husband, the condemned man.

The "Monster's Ball," the night of the condemned man's execution, is shown through a series of cross cuts, which visually link Hank and Leticia. Hank and his son watch over the prisoner as Leticia and her son watch television. The camera frames the prisoner's last meal, which is, like Hank's chocolate ice cream, served with plastic utensils. As Leticia runs out to buy mini-bottles of Wild Turkey, her significantly fat son munches on chocolate bars. Like Hank, Leticia and Tyrell are characterized through their respective oral fixations, forms of gratification that indicate each character's lack of equilibrium. This is important.

As with Hank's vomiting the movie clearly sets up its operative signifiers on the body. Leticia slaps her child for sneaking candy bars just as she yells at him for walking in the street. Her physicality can be seen to indicate her ineffectiveness as a mother as well as her frustration. Similarly the scenes of Hank's son and then of Hank with Vera, a white prostitute, are inserted to indicate their respective emotional or mental states. After mechanical, business-style sex from behind with Vera, Sonny asks her if she would like to go out, maybe for a drink. It is a rather dark, pathetic scene, which indicates, among other things, Sonny's loneliness. Shortly after Sonny's suicide in an almost identical scene we see Hank with Vera, though here Hank sends Vera off without "performing."

While these signifiers come across as clear indicators of different characters' mental states, they operate as open signifiers. Tyrell does not say that he eats because he misses the father. And Leticia does not say she drinks because she is lonely and frustrated, sexually or otherwise. The white prostitute is there to con- 


\section{Ethnic Studies Review Volume 26: 2}

vey masculine mental distress. Though Sonny never says he feels lonely, the scene with Vera is loaded with indicators that allow us to see, among other things, that he is. With Hank Vera asks a casual question about Sonny, and Hank changes his mind about wanting to have sex with her. Thus after a series of scenes showing an expressionless father efficiently cleaning up after his son's suicide and hurrying the funeral, we are able to see that, deep down, Hank is truly distressed. The film's unhurried pace underscores these actions. It is a pace that encourages the audience to project significance onto such physically rendered scenes.

The film's style of depicting its characters and projecting significance onto their physicality is, perhaps, best exemplified in the tremendously memorable and marketable scene in the movie -the first sex scene between Hank and Leticia. Obviously in this scene we are shown that both these characters do, indeed, alleviate mental distress through physical gratification.

The sex scene is about as raw as sex scenes in mainstream films go. Rather than the typical series of body parts shown in close up, the scene is shot in medium and long shot so that we see the characters as whole people. The sex is choreographed to show Hank's original impetus to doggy style penetration, which harkens back to the prostitute sex, but Leticia turns around, and even after Hank is satisfied, Leticia is shown getting off. Leticia's gratification is insistent because she is a physical gal. When Leticia says she needed that and when Hanks tells Leticia she has made him have feeling for the first time in a long time, we believe them. While the film has accustomed us to seeing physical action as indicating the character's inner world, the sex act now compels Hank and Leticia for the first time to express themselves to each other.

We also know that this is a significant scene because it is intercut with momentary shots of hands inside a bird cage. Obviously the hands and bird are meant to be seen metaphorically, yet, while the inclusion of these shots appears almost pretentiously significant, their significance is ambiguous. Sure-sex is release. But is Leticia being set free? From what? Or can we assume that sex with Leticia is responsible for releasing Hank from his emotional cage? Like a graphic and then metaphoric highlighter of itself, the movie's rendering of the sex act lets us 
know it's a significant scene, just as the scene helps establish that this is a serious, significant movie. None of the golden, soft-glow romantic silhouettes or crescendo "ahh-ahh" music of Hollywood sex scenes here. This movie is stark. It presents the facts of life hard. This makes it "real." The sex scene lends to the film a note of legitimacy, a high-minded seriousness that identifies the film as a serious one.

But most importantly we know this is a serious film because it deals so explicitly with an interracial relationship--an interracial relationship between a white man and a black woman. This makes all the difference.

Certainly interracial relationships have occurred before on the big screen. Think about the relationships between white women and black men that have been on the big screen. Try to imagine seeing Julia Roberts and Denzel Washington expressing their mutual admiration for each other in, say, the back law offices in Pelican Brief (Alan J. Pakula, 1993)) in any way even remotely similar to what occurs between Berry and Thornton. Certainly we would like to see it happen, but we know it would not. Kiss the Girls (Gary Fleder, 1997), High Crimes (Carl Franklin, 2002), The Bone Collector (Phillip Noyce, 1999), or The Long Kiss Goodnight (Renny Harlin, 1996) -films that feature a black man with a white woman have their relationship remain, sexually, squeaky clean. Though these films' narratives would typically allow for the romantic interlude or even the potential promise of romance, they consistently deny the interracial couple as a romantic couple. Films of this sort seem to use race to equalize the pair, to establish comradery over hierarchy. This is evident when contrasting any of these characters along side the usual white male protagonist. Typically the woman becomes the love interest or the black man operates as the buddy-sidekick. Even within a more imaginable action cop meets femme fatale scenario, a Wesley Snipes meets Sharon Stone, it is doubtful we would see a sex scene of this type. We assume that in the world according to Hollywood sexual desire between a black man and a white woman remains highly problematic.

Spike Lee's Jungle Fever (1991), in fact, highlights just that. In Jungle Fever problems concerning the black male/white 


\section{Ethnic Studies Review Volume 26: 2}

female romance circle around the concern the problem of lusting after the racialized other. In general there is the problem of the lead black man standing in for generalized black masculine desire. A black man choosing a particular white woman, appears as a black man who prefers white women over black women, a guy who makes a fetish of the white body. Clearly this is not okay for a male protagonist. In Jungle Fever Lee has successful architect, Wesley Snipes, put aside his happy home life, the good wife and child, to dally on the white side of the tracks. Here sexual curiosity with regard to the white woman destabilizes the black home and community. With the Italian-American temptress, Annabella Sciorra, comes the problem of the white woman's desire. The overly sexualized image of the black masculine body becomes her object of curiosity.

When the white female's desire, always a bit problematic for the movies, hones in on the black male, he comes to stand in for erotic masculinity; the woman becomes owner of the gaze. Typically women who own the gaze are femme fatales, our Sharon Stones, controlling women who are not contained within the ideology of romance and true love. As with any movie calling attention to a white woman's sexual desire, the femme fatale narrative circles around the problem of the unwholesome woman whose "unnatural," deviant sexuality leads good men astray. This is made emphatically clear in Bad Company (Damian Harris, 1995), where we watch Laurence Fishbourne and Ellen Barkin engage in a fully clothed quickie sex scene. Here desire and lust are everything, and the sex act, void of sensuality or intimacy, is anything but romantic.

The femme fatale is the white woman, usually blonde, who is both sexual and in charge of her sexuality. While the sex scene informs us that Leticia is sexual and sexually experienced, Halle Berry is not blonde, and her Leticia is hardly a femme fatale. Leticia is, if anything, characterized by her lack of power, of control, of authority. She is someone who has bad things happen: her husband is executed after eleven years on death row; her car breaks down; she loses her job; her son is killed by a hit and run; she is evicted. Leticia's anger at her son's misbehavior is typical of her lack of authority, of her inability to control her son, of her frustrated attempts to be in control. These are not the 
problems of a femme fatale.

Here you can see how Leticia's characterization as a victim is constructed using race. If Leticia were white, she would be associated with trailer parks and white trash precisely because she would be characterized by her inability to get it together. If Leticia were white, she would have had a social world associated with her waitress job, her son, and her mortgaged house; however, despite working in a people-oriented position with the colleagues and customers of food service, despite her son's social world, one that creates a world of parents, playgrounds and school, and despite the fact that she has occupied the same little house in the same small neighborhood for more than a decade, Leticia is completely alone. She is without friends or even friendly neighbors, and when her son dies, she is without family. When Hank's son dies, Hank continues to be a part of a social world, which he gradually alters by quitting his job and befriending his black neighbors. While Hank makes his world, Leticia is the lost, or evicted, lonely soul.

Monster's Ball reiterates some of the conventions characteristic of representations of black women with white men. As usual, in these movies, the black woman is, socially speaking, alone; the black woman enters the white man's world alone. Typically found along side the white action hero she is generally either the pleasantly sexual and eventually adoring sidekick, as with Vanessa Williams and Arnold in Eraser (Chuck Russell, 1996), or exotic, as with Thandie Newton and Tom Cruise in Mission Impossible II (John Woo, 2000). In Executive Decision (Stuart Baird, 1996), Berry herself is the sidekick stewardess who helps Kurt Russell and a team of marines disarm a group of onboard terrorists. Sure, she is scared, but she is tougher than her blonde co-workers, and she helps the hero land the 747 by reading directions from the flight manual. At the end of the movie she and Kurt drive off into the night for coffee. More interesting is Berry's role in Bulworth (Warren Beatty, 1998) where she helps to establish that Warren Beatty's Senator Bulworth is a good guy-not only is he concerned with civil rights, he is sexually attracted to her. She delivers a short lecture on problems concerning black community leadership considering the fact that black men are killed off; her character is responsible for 


\section{Ethnic Studies Review Volume 26: 2}

bringing the Senator to the hood where he receives an insightful education from the local drug dealer, and, of course, there is sexual attraction, which shows that the senator is not only human but likeable.

If a black woman is not masculinized or made the Aunt Jemima Oracle Lady, she is depicted as the dark exotic or erotic object of desire. In Monster's Ball the camera work as well as Berry's characterization of the isolated Leticia serves once again to establish the black woman as a sexual body. When Hank's father meets Leticia, he reminds us of just that. He too, back in his day, enjoyed "black pussy."

But, we say, Hank is not like that! Hank is not just after sex! Here we have a major indicator of how the movie's pivotal core is constructed around Hank's redemption. The fact that Leticia is first and foremost a sexualized body is evaded through the film's evidently serious rendering of inner turmoil. Both Hank and Leticia have inner turmoil. Hank's father does not. This inner turmoil, rendered through the body, lends the sex scene an aura of meaningfulness. And the graphic, raw quality of the sex indicates that this is a serious movie, which is further established through its serious interracial theme. Yet, in the end, the movie is constructed around Hank's individual epiphany, his transformation, his becoming a real man, which includes not being a racist.

Whether an audience interprets the sex scene between Leticia and Hank as a love scene might well have to do with contemporary attitudes regarding sex, romance, and love. Regardless, the series of events that follow indicate a major transformation in Hank's character. Whether we attribute them to sex with Leticia-Leticia's ability to let Hank "feel"--is open. The important thing is Hank's transformation; the audience can read the causal impetus as they choose.

Hank buys the service station showing that now Hank is going to serve people, not execute them. By white washing the house he clears away the past. By putting his father in a home he breaks with the father's authority. And Hank is particularly nice to Leticia. We know he cares about her because he names his newly procured gas station for her. He gives her his son's pick up. He gives her a place to stay at his house. And, of 
course, there is the oral sex.

In the meantime, Leticia gets to be the damsel in distress, and if there is one thing you can say about Leticia, she has every reason to be distressed. Although different from the distressed damsel played by Whitney Houston in The Bodyguard (Mick Jackson, 1992), when Hank comes to the rescue Laticia, like Kevin Costner, he becomes a better man for it. He will protect and take care of her. Leticia does, after all, need to be taken care of. She still is not given much control over her life, but she is given a relationship, which is pretty much the best thing any woman can ask for.

Leticia can trust Hank to take care of her. He is going to take care of her instead of his father; he can give, and she can appreciate him for being such a giving guy. He has become a concerned and giving sexual partner, a real man!, worthy of being appreciated and loved. Hank's transformation confirms that, deep down, he is a nice guy.

Hank's transformation inscribes simultaneously the shedding of racism with his shedding of job and father. While on the one hand Hank's racism is superficial-irrelevant and easily dismissed-it serves, on the other, to ground the film's claim to significance. Looking back Hank's racism is made explicit only on two occasions. The first is the incident with the shotgun when his father complains about the black boys on the property, and the second comes when he calls a co-worker "nigger." After that there are various scenes that might indicate racism but by no means explicitly do so. The explicit examples of Hank's racism are inscribed into attitudes associated with this father and an almost militaristic devotion to a masculine code. The father's masculine code requires recognizing authority and following the rules. It is about recognizing power and control and about controlling one's emotions. The emotional is feminine, which is weak. After watching Sonny shoot himself, the father contemptuously remarks that the boy was weak, like his mother. The type of masculinity associated with the father is therefore readily recognized as bad, insensitive masculinity.

The second explicit demonstration of Hank's racism occurs on the job, again, a job clearly associated with the father. As with American History X (Tony Kaye, 1998), another popular, 


\section{Ethnic Studies Review Volume 26: 2}

significant film showing the white protagonist shedding his racism, Hank's racism is understood through the father who has been responsible for teaching his son the racist mantra. The father in American History $X$ is a fireman who, once again, associates racism with civil service, with institutional traditions, oldfashioned notions of doing the right thing and following orders. Like his father, Hank is a corrections officer in charge of state executions, and Hank's anger at his son, which compels him to call a co-worker "nigger," is triggered by the son's emotional response to the execution. Here the father's abhorrence of weakness and emotion is put in the context of doing the job right, of providing a good execution. The issues of racism and class inscribed within the penal system and the psychic costs on the individuals performing sanctioned executions are, again, evaded. They are solved when Hank quits his job and buys a service station. Hank quits racism.

Racism is put aside in much the same way Hank puts his father in a home. Overcoming racism is overcoming the father, which in the case of Hank's father also indicates having the wrong attitudes about sex and women. Here being a bigot is connected or linked with outdated ideas concerning masculine sexuality. Fortunately that is all over by the end of the movie, as Hank is shown to have learned to be a considerate lover.

In the movie's final scene Hank holds out his plastic spoon of chocolate ice cream for Leticia, and she accepts it. Perhaps the plastic spoon links Hank with Leticia's husband-Hank too is guilty, and she is there to forgive. Does it matter? At the end of the day or by the end of the movie the film's treatment of the interracial relationship is all about the white male-his need to become emotionally whole, to "overcome" racism and bigotry so that he can "feel." His sensitivity training, or newly found ability to express his feelings, occurs as he overcomes his father and is properly appreciated by Leticia for being such a great guy. For Leticia, a relationship is pretty much the best she can ask for.

Clearly interracial romance is presented as problematic for mainstream audiences. The representation of romance in Monster's Ball is particularly problematic because it is made significant both in the acclaim that the film received and in the way that it which it normalizes the decontextualized black female 
body-a body that can and is used to construct and develop the identity of the white male protagonist, thus suggesting that interracial relationships are not based on understanding and equality but rather on the benevolence of white men and the exoticism and eroticism of the black female body. In Monster's Ball Leticia is constructed as a victim who lacks agency so that Hank can take charge of both their lives.

Moreover, the film's approach to racism as an individual choice in which romance is the catalyst for change, denies the significance of institutionalized racism (e.g. the penal system) and the role of society at large. Monster's Ball illustrates how a narrative of interracial romance submerges or dismisses that which it constructs as important-racial justice, by representing racism as a problem that can be easily identified and fixed through "love."

\section{Notes}

1 Vladimir Nabakov. Lolita (New York: G.P. Putnam's Sons, 1955), 317.

This applies to films across the races -from The Joy Luck Club (Wayne Wang, 1993) and Double Happiness (Mina Shum, 1994) to Mississippi Masala (Mira Nair, 1991). Different romantic narratives, from Sidney Poitier's successful black man in Guess Who's Coming to Dinner (Stanley Kramer, 1967) to Ken Norton's "historical" slave figure in Mandingo (Richard Fleischer, 1975), can be seen to indicate different notions of, and shifting attitudes toward black masculinity, which goes beyond the scope of this paper.

2 Although Halle Berry won the academy award, Hanks' character opens the movie, and, as critics at the time appear to have picked up, he is the primary actor within the film's narrative of interracial romance. As with A.O. Scott, writing for the NY Times: Hank Grotowski (Billy Bob Thornton) is, like his father and his son, a Georgia corrections officer. Leticia Musgrove (Halle Berry) is a waitress struggling to make end meet and to raise her 12-year-old son. She is also the widow of a man whose execution Hank helped to conduct. The relationship between Hank and Leticia, a relationship born of chance, moral reflex and desperate need, is at the center of Monster's Ball."

3 In fact, this character-type has become so normalized that by the time the conscientious but down trodden father of John Q. resorts to holding up a hospital in order to get the heart transplant that will save his son, we're rooting for him. The ludicrously happy ending -the heart arrives in the nick of time, the insurance executive is smitten with 


\section{Ethnic Studies Review Volume 26: 2}

remorse- is justice restored. Granted, this is a Hollywood solution, but it offers the only possible happy solution to a problem that has come to appear as a natural fact of life. The conscientious father of Changing Lanes, beaten time and time again, will, in the end, depend on the goodness of Ben Affleck to put things right with his family. Again, the normalization of the black man's plight, which makes it almost impossible to conceptualize a (non-violent, legal) narrative alternative, turns the white man into a hero.

4 Isabel C. Santaolalla, The Fever and the Itch: Matching Plots in Spike Lee's Jungle Fever in Terms of Endearment, ed Peter William Evans and Celestino Deleyto (Edinburgh: Edinburgh U P, 1998).

5 This situation of a black woman entering the white (mainstream) world is not limited to films with romantic narratives. Films such as with Corrina, Corrina (Jessie Nelson, 1994), Jumpin Jack Flash (Penny Marshall, 1986), Sister Act (Emile Ardolino, 1992), and Boys On The Side (Herbert Ross, 1995) have Whoopi Goldberg enter a white world. Similarly, this situation has also been known to extend to black male stars, such as with Eddie Murphy in Beverly Hills Cop (Martin Brest, 1984) and its sequels.

6 Sharon Willis, 'Style', Posture, and Idiom: Tarantino's Figures of Masculinity in Reinventing Film Studies, ed Gledhill, Williams (London: Edward Arnold, 2000). In particular, Willis points out how, for Tarantino, a white character can use the term "nigger" as a cuss word because he has a black wife, and is therefore exempt from rules which apply to ordinary whites (p.289). This is also found in a buddy movie like Gridlock'd (Vondie Curtis-Hall,1997), a white character, Tim Roth can use the word "nigger" with impunity because he's pals with a black guy/buddy, Tupac Shakur. In other words, a white character's alignment with blacks helps to exempt the white character from dispersions of racism. Similarly, in movies such as Requiem for a Dream (Darren Aronofsky, 2000), such alignment for the white protagonist helps to establish or identify him as a "good guy."

7 Tania Modleski, Feminism Without Women: Culture and Criticism in a "Postfeminist" Age, (New York: Routledge, 1991), pp 132-4. Also in Nicole Matthews, Comic Politics: Gender in Hollywood comedy after the New Right (New York: St. Martin's Press, 2000), pp 90-8. Modleski points out that either the black woman is either excessively woman, or not a woman at all, which accounts for some of the masculinized roles of Whoopi Goldberg.

8 Berry won the Academy Award for Best Actress for her role in March 2002-acknowledging her performance as an actress, as well as highlighting the significance of her character. Leticia, as well as Berry, were recognized by the Academy of Motion Pictures Arts and Sciences. 